\title{
Delayed umbilical cord clamping after childbirth: potential benefits to baby's health
}

This article was published in the following Dove Press journal:

Pediatric Health, Medicine and Therapeutics

14 November 2014

Number of times this article has been viewed

\section{Christina Uwins' \\ David JR Hutchon ${ }^{2}$ \\ 'Department of Obstetrics and Gynaecology, Croydon University Hospital, Croydon, ${ }^{2}$ Department of Obstetrics, Darlington Memorial \\ Hospital, Darlington, UK}

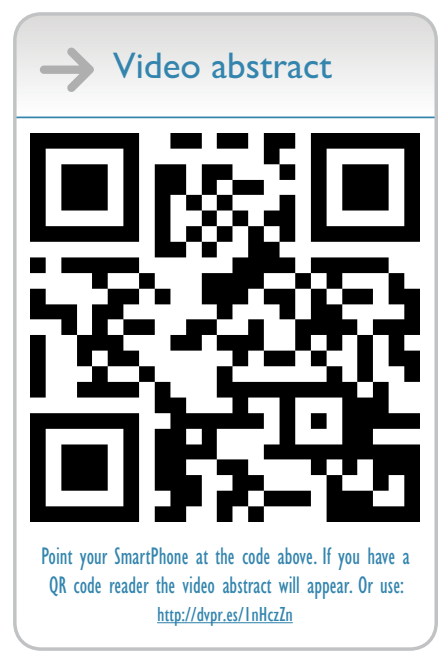

Correspondence: David JR Hutchon Darlington Memorial Hospital, Hollyhurst Rd, Darlington, County Durham DL3 6HX, UK

Email djrhutchon@hotmail.co.uk

\begin{abstract}
Early cord clamping was initially introduced as part of the package of care known as "active management of the third stage", which was implemented to reduce postpartum hemorrhage. It has now been shown to provide no benefit to the mother and to result in harm to the neonate. The clinical trial evidence relating to delayed cord clamping compared to immediate cord clamping is presented and the physiological rationale for delayed cord clamping is discussed in this paper. Most organizations (eg World Health Organization (WHO), Royal College of Obstetricians and Gynaecologists (RCOG), Resuscitation Council (UK), The International Federation of Gynecology and Obstetrics (FIGO), International Confederation of Midwives, International Liaison Committee on Resuscitation (ILCOR) and the European Resuscitation Council) now advise a delay of 1-3 minutes before clamping the cord in term and preterm infants, and clinicians need to be aware of this change. Healthy neonates benefit from a more physiological and gentle transition from placental to pulmonary respiration, and we explain why this benefit should be provided to all neonates until there is any evidence to the contrary. The harm of early cord clamping is not limited to anemia and iron deficiency, and evidence for a wide range of possible harms of early cord clamping is presented. The need for resuscitation is one of the most common concerns, and ways of overcoming these concerns are described.
\end{abstract}

Keywords: transition, cord clamping, hypovolemia, intraventricular hemorrhage

\section{Introduction}

Worldwide, babies are born every day with a varying degree of intervention. Some are born at home with little or no professional support, and others in the hospital environment with a multitude of monitoring and interventions. In the UK, we have devoted much time and money into supporting natural childbirth in the "normal/low-risk" patient, with the development of birthing centers and dedicated home birth teams. The thinking around such investments is that promoting normality and providing a relaxing environment reduces intervention and increases the likelihood of a normal vaginal delivery. In these situations, a physiological third stage, where the cord is left intact until it has stopped pulsating, or indeed until the placenta has been delivered, is becoming increasingly more common. This not only allows full placental transfusion to take place, but also promotes mother-baby bonding with skin-to-skin contact, which in itself promotes regulation of temperature and heart rate in the neonate. Additionally, leaving the cord intact in this way allows a gentle transition from fetus to neonate, ie, the "neonatal transition" period. A physiological third stage is one way to ensure that blood that was circulating through the placenta at the time of delivery is not trapped there by premature clamping of the umbilical cord. This blood is used by the baby to fill the newly opened up pulmonary 
circulation with the onset of pulmonary respiration. This delay in clamping of the umbilical cord has been shown to benefit term infants (Table 1), with higher early hemoglobin concentration and increased iron reserves up to 6 months after birth ${ }^{1,2}$ and no statistically significant increase in jaundice or polycythemia in the latest randomized controlled trial. ${ }^{1}$

In preterm infants, the benefits are even more marked (Tables 2 and 3). Delaying cord clamping by 30-120 seconds in preterm infants resulted in fewer babies requiring transfusions for anemia, better circulatory stability, reduced risk of intraventricular hemorrhage (all grades), reduced risk of necrotizing enterocolitis, and less late-onset sepsis. ${ }^{3}$

We have come a long way towards supporting normality in low-risk pregnancies. Our "high-risk" pregnant women, in contrast, are experiencing and possibly have already experienced extremely difficult, complicated, and stressful pregnancies. This group of women is at significant risk of complications antenatally, during labor, and postnatally. They may have traumatic deliveries compounded with early separation from their babies. They may not be able to have uninterrupted skin-to-skin contact, and subsequently are at risk of experiencing difficulties with bonding and establishing breast feeding. It is in these women that it is even more important to promote as much normality as possible within the confines of necessary monitoring and provide a consistent supportive relaxing environment, throughout pregnancy, labor, and after delivery. This helps to avoid unnecessary intervention and subsequent associated morbidity.

The one common denominator of most high-risk deliveries is the immediacy with which the cord is clamped. This is in stark contrast with the gentle transition now often accorded to low-risk deliveries. As we will discuss in detail, these babies have often been exposed to physiologically stressful labors. It is therefore even more important that they are given the opportunity to transition in as gentle a way as possible, allowing a stable pulmonary, cardiovascular, and cerebral hemodynamic transition, thereby avoiding the recognized complications of immediate cord clamping, which are even more marked in both preterm deliveries and labors complicated with cord compression, such as those with pathological cardiotocograms, nuchal cords, bradycardia, and shoulder dystocia.

In high-risk pregnancies, there is often a concern about an increased risk of post-partum hemorrhage, which remains the leading cause of maternal death worldwide. In the 1960s, a package of care known as "active management of the third stage" was implemented to reduce postpartum hemorrhage. This package of care is comprised of three components: 1) administration of uterotonic drugs; 2) immediate cord clamping; and
3) controlled cord traction to deliver the placenta. These recommendations were adopted worldwide in both developed and developing countries as an effective means of reducing maternal mortality from postpartum hemorrhage. However, subsequent review of the individual components of "active management of the third stage" has shown that, of these three interventions, only administration of uterotonic drugs has any proven benefit to reduce postpartum hemorrhage. ${ }^{4}$ However, routine practice over the last 50 years is a difficult habit to change.

Immediate cord clamping was not always common practice. Even with the invention of the cord clamp by Edward Magennis $^{5}$ in 1899, it was clearly specified that the clamp should only be used once the cord had turned white and ceased to pulsate, as previously being taught by Charles White ${ }^{6}$ (18281913) who wrote: "the common method of tying and cutting the navel string in the instant the child is born, is likewise one of those errors in practice that has nothing to plead in its favour but custom ..." and by Erasmus Darwin? (1831-1902), English physician and grandfather to Charles Darwin:

Another thing very injurious to the child, is the tying and cutting of the navel string too soon; which should always be left till the child has not only repeatedly breathed but till all pulsation in the cord ceases. As otherwise the child is much weaker than it ought to be, a portion of the blood being left in the placenta, which ought to have been in the child. ${ }^{7}$

How many obstetricians or pediatricians consider in detail what is happening to a recently delivered neonate who seconds before was referred to as a fetus. At the point when the neonate transitions from the in-utero environment to an air-breathing one, the fetal circulation needs to change to the neonatal circulation. In utero, fetal shunts preferentially shunt oxygenated blood to the fetal brain. The ductus venosus bypasses the liver, delivering oxygen-rich blood from the umbilical vein directly to the inferior vena cava and the right side of the heart. The foramen ovale allows blood to enter the left atrium from the right atrium, preferentially delivering well oxygenated blood to the brain, and the ductus arteriosus allows blood to bypass the unused pulmonary circulation (Figure 1). At the moment of birth, if the placental circulation is abruptly interrupted (with a cord clamp), the neonate has to immediately convert from its fetal circulation, closing off these shunts, to a neonatal circulation, and at the same time recruit blood (from its now reduced circulating volume) to open up the previously unused pulmonary circulation. It is not surprising, when the volume in which the blood is circulating is increased, without increasing the amount of blood, that hypotension and bradycardia will occur. ${ }^{8}$ Conversely, if the cord is left intact and placental 


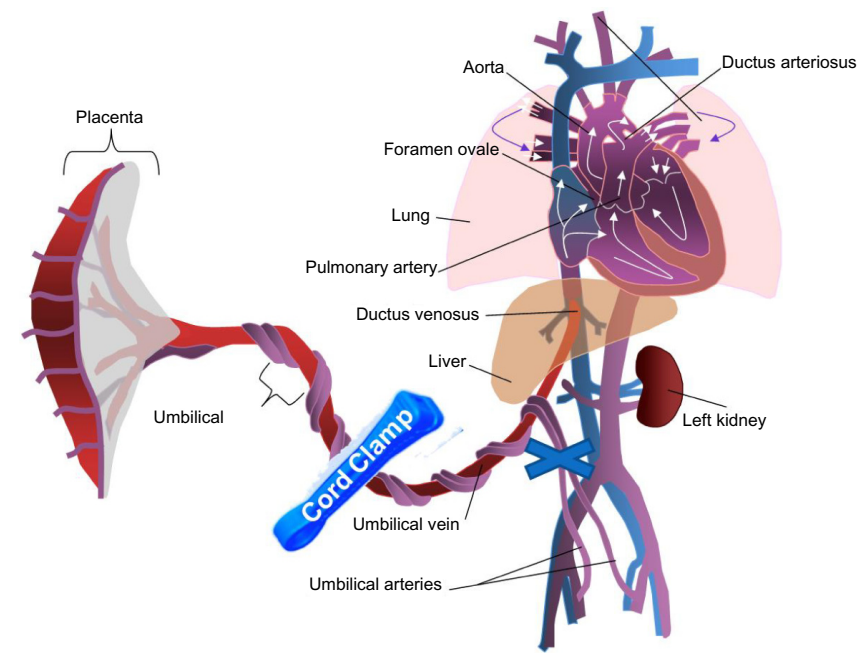

Clamping cord immediately:

Reduces preload to the heart by blocking $40 \%$ of venous return from the placenta via the umbilical vein

Increases afterload dramatically by obstructing the umbilical arteries thus increasing peripheral vascular resistance

$=$ Reduced cardiac output

Figure I Fetal circulation.

transfusion is allowed to continue unhindered, the blood returning from the placenta is used to fill the newly opened up pulmonary circulation, thereby minimizing swings in left ventricular output and consequently arterial pressure. ${ }^{9}$

\section{The neonatal transition}

During fetal life, de-oxygenated blood is delivered to the placenta via both of the umbilical arteries, circulates through the placenta, and oxygenated blood is then returned to the baby through the umbilical vein. Clamping the cord stops the blood flow to the baby from the umbilical vein, abruptly reducing the preload to the heart by up to $40 \% .{ }^{10}$ At the same time, occlusion of the umbilical arteries abruptly increases the cardiac afterload by increasing peripheral vascular resistance. This results in reduced cardiac output (Table 4).

After delivery, ventilation of the lungs reduces pulmonary vascular resistance, which increases pulmonary blood flow. Allowing this to happen prior to cord clamping has a two-fold effect. The portion of the blood circulating within the placenta is moved to fill the new pulmonary circulation, increasing pulmonary blood flow. This increase in pulmonary blood flow can then take over supplying the preload to the heart, previously provided by blood from the umbilical vein. If ventilation/breathing occurs before cord clamping, the baby is able to avoid the loss of venous return and the decreased left ventricular output caused by cord clamping. This minimizes swings in left ventricular output and arterial pressure that are associated with the increased risk of intraventricular hemorrhage seen in immediately cord-clamped preterm babies. ${ }^{9}$ In a study by Farrar et al, ${ }^{11}$ up to $204 \mathrm{~mL}$ of blood can be trapped in the placental circulation if the cord is clamped immediately. This equates to $30 \%-40 \%$ of the circulating volume.
It is astounding that many healthy term neonates appear to tolerate this.

A fascinating study by Bhatt et $\mathrm{al}^{9}$ looked in depth at the physiological changes associated with cord clamping and ventilation using a fetal lamb model. This study was designed to reflect the situation of delivery of a preterm neonate at approximately 26 weeks' gestation. Prenatal surgery was performed on lambs to implant catheters into the pulmonary and carotid arteries and probes to measure pulmonary, carotid, and ductus arteriosus blood flow. The lambs were then delivered 3-4 days later. In the first group, the umbilical cord was clamped at delivery and then ventilation was established at 2 minutes. In the other group, cord clamping was delayed for 3-4 minutes until after ventilation was established. This study beautifully illustrated that if umbilical circulation is occluded by cord clamping, before the pulmonary circulation is properly established, marked adverse changes on the circulation result. However, if clamping is carried out 3-4 minutes after the onset of respiration and after the pulmonary circulation is well established there are no significant changes in heart rate, cardiac output, or the cerebral circulation. Marked bradycardia was shown to occur after early cord clamping and at the same time a short rise in carotid arterial pressure occurred, followed by marked hypotension, and a fall in cardiac output and cerebral circulation. Cardiovascular instability is thought to explain the increased risk of intraventricular hemorrhage seen in immediately cord-clamped preterm babies. ${ }^{3}$

\section{Physiology of cord clamping in situations of fetal distress}

Delayed cord clamping is vital in situations such as shoulder dystocia, nuchal cord, and pathological cardiotocography, 


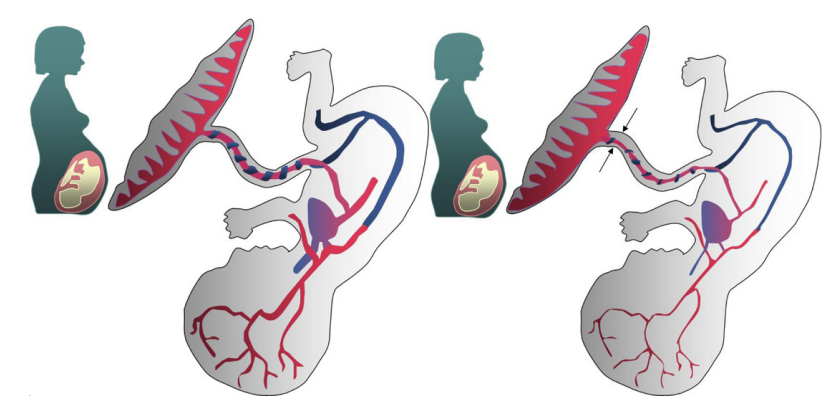

Figure 2 Effect of in utero cord compression. Low pressure venous return is impeded more than the high pressure arterial supply to the placenta, leading to congestion within the fetal side of the placental bed and reduced blood circulating around the fetus.

where cord compression has occurred immediately prior to birth. During cord compression, the thin-walled umbilical vein will be occluded while the thicker-walled umbilical arteries remain patent. This results in a net movement of blood away from the fetus towards the placenta (Figure 2). The resulting neonate will have a reduced circulating volume. Prior to delivery, pressure on the body of the fetus from the vaginal walls acts somewhat like an anti-shock garment, encouraging blood to move from the peripheral circulation to the central circulation. ${ }^{12}$ Following delivery, this pressure is released, causing blood to move back into the peripheral circulation, reducing central venous pressure, and decreasing blood pressure. If at delivery the cord remains intact, or is milked, this lost blood volume can return to the baby from the placenta, preventing the otherwise inevitable hypovolemia and hypotension. However, if the baby in this situation is subjected to immediate cord clamping, the resulting severe hypovolemic shock with reduced blood flow to the heart could cause sudden cardiac arrest. ${ }^{12}$

\section{Effect of gravity on volume of placental transfusion}

Current recommendations regarding delayed cord clamping have included that the infant be held at the level of the vagina, or below, for more than one minute. This is understandably cumbersome and interferes with immediate contact with the mother and can be technically difficult to perform in the situation of cesarean section. The assumption has been that holding the recently delivered baby below the level of the placenta would aid placental transfusion by having gravity in its favor; however, surprisingly, this does not seem to be the case. A very recently published multicenter, randomized, non inferiority trial by Vain et $\mathrm{al}^{13}$ compared "vigorous" babies born vaginally and held at the level of the vagina with those held on the mother's abdomen or chest for a period of 2 minutes before clamping the umbilical cord. The newborn babies were weighed at the time of delivery and after cord clamping. Weight was used as a proxy for placental transfusion volume. The prespecified noninferiority margin was $18 \mathrm{~g}(20 \%)$. A total of 197 babies held at the level of the introitus were compared with 194 babies held on the mother's abdomen or chest. A mean weight change of $56 \pm 47 \mathrm{~g}$ (95\% confidence interval 50-63) was found in the babies held at the level of the vagina compared with $53 \pm 45 \mathrm{~g}$ (95\% confidence interval 46-59) for the babies held on the mother's abdomen or chest. The difference between the two positions was $3 \mathrm{~g}(95 \% \mathrm{CI}-5 \cdot 8$ to $12 \cdot 8 ; P=0 \cdot 45)$. The study concluded that mothers could be safely encouraged to hold the baby on their abdomen or chest because the position of the baby prior to cord clamping did not affect placental transfusion. Simplifying the practice of delayed cord clamping (or the perception of it) may increase obstetric compliance, thereby reducing iron deficiency in infancy and enhancing maternalinfant bonding. ${ }^{13}$

\section{Are there any alternatives to delayed cord clamping?}

In 1954, Colozzi wrote "I have seen several infants with asphyxia pallida who were very pale and listless, with a rapid pulse and a very weak cry; with gentle, slow, methodical cord stripping, they were transformed within a few minutes to ruddy, lustily-crying infants." 14

In situations where time is critical, such as severe maternal hemorrhage or where immediate extensive resuscitation is required, "cord milking", also referred to as "cord stripping", can be used. This is a technique whereby blood is transferred from the placenta to the baby by milking the cord towards the baby and pushing the blood in the direction of the baby. The aim is to move blood from the placental bed towards the baby more rapidly than would happen from just delaying clamping of the cord. As milking the cord happens over a more rapid time frame than delayed clamping, it can be argued that cord milking is not physiological. However, in the pathological situation of cord compression, it does provide a more rapid transfer of blood which may restore the neonatal blood volume more rapidly.

In a randomized controlled trial by Erickson-Owens et al, ${ }^{15} 24$ women were randomized to either immediate cord clamping ( $<10$ seconds) or umbilical cord milking $($ milked $\times 5)$ at birth. The milking group was found to have a smaller placental residual blood volume (30\% less) and higher hematocrit levels at 36-48 hours. In the immediate cord clamping group, five infants were found to have a hematocrit $\leq 48 \%$, indicative of anemia. 
In another randomized trial, Rabe et $\mathrm{al}^{16}$ compared cord milking with delayed cord clamping as methods to increase placental transfusion in preterm neonates. Deliveries before 33 weeks were included and then randomized to either standard treatment of clamping the cord 30 seconds after delivery or milking of the cord $(\times 4)$. Fifty-eight neonates were included in the trial, with 31 receiving delayed cord clamping and 28 receiving cord milking. Mean hemoglobin values for each group at one hour after birth were similar $(18.3 \mathrm{~g} / \mathrm{L}$ for the delayed cord clamping group and $18.5 \mathrm{~g} / \mathrm{L}$ for the cord milking group). There was no significant difference in need for blood transfusion between the two groups.

\section{Key findings from systematic reviews demonstrating benefits of late cord clamping}

Delayed cord clamping is supported by two recent Cochrane reviews looking at its effects in both term and preterm neonates. ${ }^{2,3}$

Table I Benefits of delayed cord clamping for term infants

Term infants $>\mathbf{3 7}$ weeks

Delaying cord clamping for at least one minute

Higher early hemoglobin concentration

Increased iron reserves up to 6 months after birth

No difference in PPH rates

Higher birth weight

No statistically significant increase in jaundice or polycythemia

Abbreviation: PPH, post partum haemorrhage.

Table 2 Benefits of delayed cord clamping for preterm infants

Preterm infants 24-37 weeks

Providing additional placental blood to the preterm baby by delaying

cord clamping by $30-120$ seconds resulted in

Fewer babies needing transfusions for anemia

Better circulatory stability

Reduced risk of intraventricular hemorrhage (all grades)

Reduced risk of necrotizing enterocolitis

Reduced late-onset sepsis

Table 3 Benefits of DCC for very preterm infants

\begin{tabular}{l}
\hline Very preterm infants $<\mathbf{3 0}$ weeks \\
Delaying cord clamping by $20-45$ seconds \\
2-3-fold reduction in intraventricular hemorrhage \\
Reduced need for blood transfusions \\
Greater mean blood pressures in the first hours of life \\
No difference in Apgar scores at 5 minutes/body temperature \\
Just short of statistical significance for halving of mortality with DCC \\
in these infants
\end{tabular}

Abbreviation: DCC, delayed cord clamping.
Table 4 Effects of early cord clamping on circulation

Early cord clamping - proven adverse effects

Variable degree of hypovolemia

Severe hypovolemia when preceded by intrapartum cord compression

Hypoxia

Sudden decrease in preload to the heart

Increases afterload dramatically by obstructing the umbilical arteries, thus increasing peripheral vascular resistance

Fall in cerebral circulation

Fall in cardiac output

Bradycardia

\section{Term infants $>37$ weeks}

The latest Cochrane review ${ }^{2}$ looking at the effect of umbilical cord clamping on maternal and neonatal outcomes in term infants reviewed 15 trials involving 3,911 women and infant pairs. Neonates that underwent delayed cord clamping (generally 1-3 minutes) had significantly higher mean birth weights and higher initial hemoglobin concentrations, with improvements in iron stores persisting at 3-6 months. Infants who received early cord clamping were twice as likely to be iron-deficient at 3-6 months when compared with infants who had delayed cord clamping. There was no difference in postpartum hemorrhage rates between the two groups. This Cochrane review showed that more infants in the delayed cord clamping group required phototherapy for jaundice than in the early cord clamping group. However, this part of the Cochrane review has been heavily criticized ${ }^{17}$ as a result of having relied heavily on one 12-year-old unpublished trial done by the lead author of the review in which the pediatricians were not blinded to the timing of cord clamping and the decision for phototherapy was not based on consistent bilirubin levels. Indeed, if this one trial was removed from the statistical analysis, the outcomes would show no difference in use of phototherapy.

There was no increased requirement for phototherapy in the meta-analysis by Hutton and Hassan. ${ }^{18}$ Their meta-analysis also found that delaying clamping of the umbilical cord for at least 2 minutes after birth resulted in higher hematocrit levels and improved markers of iron status over the first months of life without having a significant impact on absolute values of bilirubin and plasma viscosity during the first week of life. Additionally, the latest randomized controlled trial by Andersson et al found higher early hemoglobin concentrations and increased iron reserves up to 6 months after birth, and with no statistically significant increase in jaundice or polycythemia. ${ }^{1}$

\section{Preterm infants $<37$ weeks}

The biggest benefits of delayed cord clamping are demonstrated in preterm babies. A recent Cochrane review in 2012 looking at the effect of delayed cord clamping in 
preterm infants included 15 studies involving 838 infants of 24-36 weeks' gestation. It found that providing more placental transfusion to the preterm baby by delaying cord clamping by $30-120$ seconds resulted in increased circulating volume, improved blood pressure and circulatory stability, fewer babies needing transfusions, a reduced risk of intraventricular hemorrhage (all grades), a reduced risk of necrotizing enterocolitis, and less late-onset sepsis. ${ }^{3}$

\section{Very preterm infants $<30$ weeks}

An interesting meta-analysis by Backes et al ${ }^{19}$ looked at umbilical cord clamping and other placental transfusion strategies in very preterm infants $(<30$ weeks, mean gestation 28 weeks). ${ }^{19}$ This meta-analysis showed in these very preterm infants, that delaying cord clamping for 20-45 seconds led to a 2-3-fold reduction in intraventricular hemorrhage, a reduced need for blood transfusions, higher mean blood pressure in the first hours of life, no difference in 5-minute Apgar score or body temperature, and a trend towards a reduction in mortality.

\section{Long-term health benefits associated with late cord clamping}

It is now well established that delayed cord clamping improves total body iron stores for up to 6 months of age and reduces the need for blood transfusion for anemia. Within the brain, iron is important in myelin production in oligodendrocytes, and decreased availability leads to hypomyelination. Iron deficiency in children most commonly presents with poor school performance, decreased cognitive abilities, and behavioral problems. These clinical outcomes in iron-deficient children can be traced to hypomyelination, and have been shown to persist despite subsequent iron supplementation. ${ }^{20}$ Iron deficiency and iron deficiency anemia in infancy are associated with cognitive motor and behavioral deficits as well as persistent neurophysiological differences. ${ }^{21}$

Preterm babies have been shown to suffer fewer intraventricular hemorrhages when they have delayed cord clamping compared with immediate cord clamping. This begs the question whether these preterm babies are acting like canaries in the coal mines, with their more fragile bodies showing the damage that occurs to a delicate developing brain when subjected to immediate cord clamping. It is possible that in a more robust full-term infant neurological damage may go unnoticed, despite still occurring.

Many parents today are choosing to bank their baby's cord blood, either privately or altruistically, for organizations such as the Anthony Nolan Trust. Private cord banking facilities attract clients based on the promise of the potential future benefits to their baby or family from the stem cells contained within the cord blood. Marketing phrases include "your baby's cord blood may hold the key to their long-term health",22 "a simple and safe procedure", ${ }^{22}$ and "stem cells must be collected shortly after birth, and carefully stored, or they're lost forever". ${ }^{23}$ These cord blood stem cells have properties that have been shown in the laboratory to help the body repair itself. ${ }^{24}$ Currently, trials are underway looking at the potential benefits of cord blood stem cells in the treatment of many different conditions, including cerebral palsy, ${ }^{25,26}$ autism, ${ }^{27}$ pediatric stroke,${ }^{28}$ traumatic brain injury, ${ }^{29}$ and type 1 diabetes. ${ }^{30}$

A study currently being conducted in children with cerebral palsy at Duke University is one of the first placebocontrolled, randomized, crossover clinical trials of its kind. ${ }^{31,32}$ It has been started to determine whether a single intravenous infusion of a child's own umbilical cord stem cells will cure or reduce the severity of their disease. They aim to show improvements in functional status of the children, aged 12 months to 6 years, looking specifically at their cognitive, language, motor, and functioning capabilities. The authors have been quoted as saying that "If this study shows that cord blood is beneficial, it will have a huge impact on the practices of cord blood collection and banking at birth." They also state that they hope as a result of their work that "... more parents will choose to bank their child's cord blood at birth and that public cord blood banks will hold the child's blood long enough to treat the child (if needed) before being made available for public use". They hope to find out whether cord blood can be used as a treatment for cerebral palsy and also determine the beneficial effects of cord blood, such as reducing inflammation in the brain, repairing damaged brain cells, and evolving of new brain cells to replace damaged ones. ${ }^{31,32}$ Another trial also being conducted at Duke University is looking into the use of cord blood for neonatal hypoxic-ischemic encephalopathy. ${ }^{26}$ This study is examining the use of autologous umbilical cord blood infusions in term newborns up to 14 days old who have signs of moderate to severe encephalopathy at birth.

These are both interesting studies. If cord blood is found to be helpful in these situations, where the initial injury has already occurred at the time the baby was born, it begs the question whether the purpose of the cells contained within the cord blood, which, after all, are just part of the neonate's original circulating volume, is to repair any intrapartum injuries that may have occurred. Neither of the above studies states in their online summaries (ClinicalTrials.gov) how 
the cord blood is to be harvested, or whether immediate cord clamping is required in order for a sufficient quantity of blood to be harvested from the cord. The final answer may well be to allow the neonate to receive its full blood volume and to transition gently with its full complement of stem cells, rather than clamping the cord prematurely.

A report looking at the incidence of cerebral palsy over a 25-year period in north-east England ${ }^{33}$ found that the rate of cerebral palsy rose between 1980-1985 and 1990-1994 from 1.6 to 2.3 , respectively, per 1,000 singleton neonatal survivors. They found that this increase was almost entirely made up of preterm infants when compared with term infants, with little change in the rate of cerebral palsy in term infants but a significant rise in preterm infants $<37$ weeks, in which the rate rose from 5.5 to 16.8 per 1,000 neonatal survivors. The most marked rise was in the $<28$-week gestational age group. Also of note in those infants born after 32 weeks, rates of cerebral palsy were significantly higher in small for gestation infants. Although by no means proving causation, it is interesting that this increase in incidence of cerebral palsy mirrors the implementation of immediate cord clamping internationally, which first started in the 1960s but only became routine practice by both midwives and obstetricians around the 1980s when the Bristol third stage trial by Prendville et al was published. ${ }^{34}$ It is well documented in the Cochrane reviews ${ }^{2,3}$ and in a recent meta-analysis by Backes et al, ${ }^{19}$ that the harmful effects of immediate cord clamping are more catastrophic in preterm infants than in term infants.

The rates of autism have also increased since the $1980 \mathrm{~s},{ }^{35}$ with recent studies estimating that about $1 \%$ of the child population may have an autistic spectrum disorder (almost a 20 -fold rise in prevalence compared with before the 1980s). A recent meta-analysis by Gardener et $\mathrm{al}^{36}$ reported that the obstetric complications found to be significant for the later development of autism pointed to a possible role of fetal and neonatal hypoxia. Growth retardation, fetal distress, nuchal cord, low Apgar score, respiratory distress, resuscitation, aspiration of meconium, and cesarean delivery were all found to be potential risk factors. Many of these complications would be associated with early cord clamping.

Despite (unfounded) historical concerns of increased levels of jaundice and polycythemia with delayed cord clamping, the development of kernicterus has not been linked to the timing of cord clamping or even to any consistent threshold bilirubin blood level. Even with the introduction of RhoGAM to prevent Rhesus disease, cases of kernicterus still occur, and since 1994 there has been a significant increase in kernicterus. ${ }^{37}$ It has remained a puzzle as to why damage from elevated levels of bilirubin occurs in some but not all infants. In 1933, a review of a large number of case reports by Zimmerman and Yannet ${ }^{38}$ found that injury by anoxia or sepsis often preceded the post mortem findings of staining of subcortical nuclei in the brain. This was likened to the fact that intravital dyes will localize to zones of injury, leaving undamaged tissues unstained. This was also demonstrated using a rhesus monkey animal model by Lucey et al, ${ }^{39}$ where the monkeys were delivered by cesarean section and had jaundice induced by injecting bilirubin. Despite having severe jaundice, these monkeys did not go on to develop kernicterus. This group was then compared with monkeys that had been asphyxiated at birth for 10-12 minutes and then made hyperbilirubinemic. The monkeys who were asphyxiated went on to develop neurological deficits with abnormal electroencephalograms and kernicterus. At post mortem, canary yellow staining of the brain was present. The theory is that in order for kernicterus to develop, the blood-brain barrier needs to be breached, for example, by being subjected to a hypoxic injury or infection.

\section{Reasons for widespread practice of early cord clamping}

Despite no evidence of any benefit of immediate cord clamping, the practice has continued over more than the past half century. Convenience and lack of knowledge of the potential harms associated with immediate cord clamping may be some of the reasons why the practice has continued. Additionally, concerns regarding delaying resuscitation and initiation of ventilation may also be factors. These are not insurmountable barriers, as the initial steps in neonatal resuscitation (warming, drying, clearing of the airway, and stimulating the newborn) can easily be done with the cord intact prior to transfer to the resuscitaire.

With some anticipation and adaptation a number of approaches to continued resuscitation with the cord intact are possible. ${ }^{40}$ The LifeStart trolley (Inditherm plc, Rotherham, UK), a height-adjustable, compact trolley for bedside resuscitation has recently become available. As a minimum, it is essential that the infant is encouraged to establish its breathing prior to the cord being clamped, as ventilation of the lungs reduces pulmonary vascular resistance which increases pulmonary blood flow. Allowing this to happen prior to cord clamping has a two-fold effect. The portion of the blood circulating within the placenta can move to fill the new pulmonary circulation, increasing pulmonary blood flow. This increase in pulmonary blood flow can then take 
over supplying the preload to the heart, previously provided by blood from the umbilical vein. If ventilation/breathing occurs before cord clamping, the baby is able to avoid the loss of venous return and decreased left ventricular output caused by cord clamping.

As discussed previously, the recent trend for cord blood banking is another possible driver of immediate cord clamping. The American College of Obstetricians and Gynecologists specifically advises that cord clamping time should not be influenced by the need or desire for umbilical cord blood banking; however, delaying clamping of the cord will significantly reduce the volume of blood harvested because much will be passed on to the neonate as part of placental transfusion. ${ }^{41}$

The need to obtain cord blood gases for medicolegal reasons may also be a reason why cord clamping is not delayed. It is somewhat ironic that something used to defend medical practitioners regarding the quality of their care may actually be harming their patients and worsening their outcomes. Wilberg et $\mathrm{al}^{42}$ looked at the influence of delayed umbilical cord clamping at birth on arterial and venous umbilical cord blood gases and showed significant decreases in $\mathrm{pH}$ in the first few minutes after birth. In addition, as the placental circulation closes and there is less blood remaining in the cord/placenta, there may be technical difficulties obtaining the blood. It is essential that the time of cord clamping is clearly documented in the patient's delivery notes, along with the time of the first breath. Wilberg et $\mathrm{al}^{42}$ showed (see Table 3 in their paper) that even in the presence of significant intrapartum hypoxia and acidemia, recovery without active resuscitation and ventilation is possible provided the umbilical circulation remains intact.

The World Health Organization recommends delayed cord clamping, even in babies born to human immunodeficiency virus (HIV)-positive mothers and those with unknown HIV status. The rationale behind this is that, during the time between birth and cord clamping, blood flow from the placenta to the newborn is the same as during pregnancy. The World Health Organization states: "There is no evidence that 1-3 extra minutes of additional placental blood flow after birth increases the possibility of HIV transmission from mother to baby". ${ }^{43}$

As we have discussed, there is increasing evidence regarding the benefits of allowing a gentle neonatal transition and the harms of immediate cord clamping. More and more professional bodies are recommending delayed cord clamping. Clamping of the umbilical cord is a procedure that is often done quickly, almost as a reflex and without much thought. However, not honoring a parent's request for delayed cord clamping could in itself have medicolegal consequences.

\section{Recommendations for health professionals on delayed cord clamping}

Babies that have delayed cord clamping behave very differently to those subjected to immediate cord clamping. The lusty indignant cry is not so prominent a feature. Babies afforded a gentle neonatal transition by delaying the clamping of the umbilical cord are often alert, looking around, and relaxed. They may be breathing gently but not cry vigorously until the umbilical cord is finally clamped. They display better cardiovascular stability maintaining a steady heart rate and have higher mean blood pressures. Since oxygen continues to be provided though the umbilical vein along with blood volume, which helps to fill the the neonates newly opened up pulmonary circulation, the baby is seen to transition slowly and gently in situations with delayed cord clamping. This is in stark contrast to the almost immediate cry, often heard when the cord is immediately cut. With delayed cord clamping, events unfold more gradually; the delay in hearing the first cry can be incorrectly viewed as a sign of distress.

Given the mounting evidence of the harmful effects of immediate cord clamping, particularly in vulnerable infants, such as those who are preterm or of very low birth weight, many professional organizations are now recommending delaying clamping of the umbilical cord by a minimum of one minute. Table 5 summarizes the current recommendations from various professional bodies with regard to delayed cord clamping.

Most organizations are recommending a delay of 1-3 minutes before clamping the cord (Table 5). One of the barriers to fully implementing delayed cord clamping is the perceived need to clamp early in order to initiate resuscitation. In reality, the first one minute of the neonatal resuscitation protocol involves warming, drying, clearing of the airway, and stimulating the newborn, together with an accurate assessment of the parameters of heart rate, respiration, and tone. Until the value of bedside resuscitation is confirmed, for a hospital birth, where the newborn is in need of immediate resuscitation, the cord can be clamped as near to the placenta as possible, leaving the cord as long as possible before transferring to the resuscitaire to continue resuscitation. Cord milking can also be performed prior to cutting the cord. The cord should only be trimmed once resuscitation is complete.

For a home birth, there is no benefit to prematurely cutting the cord, so resuscitation should continue at the side of the 
Table 5 Current recommendations from professional organizations regarding delayed cord clamping

\begin{tabular}{|c|c|}
\hline Professional organization & Recommendation \\
\hline $\begin{array}{l}\text { WHO }(2013)^{43} \\
\text { Delayed clamping of the umbilical cord to reduce } \\
\text { infant anemia }\end{array}$ & $\begin{array}{l}\text { "Late cord clamping (performed I to } 3 \text { minutes after birth) is recommended for all } \\
\text { births while initiating simultaneous essential newborn care." } \\
\text { "HIV: WHO recommends delayed cord clamping for all women, including HIV- } \\
\text { positive mothers and mothers whose HIV status is unknown." }\end{array}$ \\
\hline $\begin{array}{l}\text { RCOG } \\
\text { RCOG statement on Cochrane review on timing of } \\
\text { cord clamping }(2013)^{44} \\
\text { Green-top guideline } 52(2009)^{45} \text { on prevention and } \\
\text { management of postpartum hemorrhage }\end{array}$ & $\begin{array}{l}\text { "The RCOG recommends that the umbilical cord should not be clamped earlier } \\
\text { than is necessary. This new study adds to the emerging evidence showing benefits } \\
\text { to delayed cord clamping, a minute after birth or when cord pulsation has ceased." }\end{array}$ \\
\hline Resuscitation Council (UK, 20I0) & "For uncompromised babies, a delay in cord clamping of at least one minute from \\
\hline Newborn life support ${ }^{46}$ & the complete delivery of the infant is now recommended." \\
\hline FIGO/International Confederation of Midwives Joint Statement ${ }^{47}$ & "Delaying cord clamping by one to three minutes reduces anemia in the newborn." \\
\hline International Liaison Committee on Resuscitation ${ }^{48}$ & $\begin{array}{l}\text { "Cord clamping should be delayed for at least I minute in babies who do not } \\
\text { require resuscitation. Evidence is insufficient to recommend a time for clamping in } \\
\text { those who require resuscitation." }\end{array}$ \\
\hline ERC guidelines for resuscitation $(2010)^{49}$ & $\begin{array}{l}\text { "Delay in umbilical cord clamping for at least I minute is recommended for } \\
\text { newborn infants not requiring resuscitation. A similar delay should be applied to } \\
\text { premature babies being stabilized. For babies requiring resuscitation, resuscitative } \\
\text { intervention remains the priority." }\end{array}$ \\
\hline
\end{tabular}

Abbreviations: ERC, European Resuscitation Council; FIGO, The International Federation of Gynecology and Obstetrics (FIGO); HIV, human immunodeficiency virus; RCOG, Royal College of Obstetricians and Gynaecologists; WHO, World Health Organization.

mother with the cord intact unless there is a need to cut the cord to resuscitate the mother, such as in severe postpartum hemorrhage. If this is needed prior to a 3-minute delay in cord clamping being completed, then cord milking can be performed and the cord left as long as possible prior to cutting.

In pregnancies complicated with rhesus or $\mathrm{ABO}$ isoimmunization, delayed cord clamping is optimal. The same logic applies as to that used by the World Health Organisation for mothers with, or at risk of, HIV, namely that delayed cord clamping should be practiced as there is no evidence that 1-3 extra minutes of additional placental blood flow after birth will adversely affect the baby. ${ }^{43}$ The blood returning from the placenta is the same blood that was circulating around the fetus before birth. Immediately clamping the cord would make an infant already at risk of anemia even more vulnerable by reducing its initial hemoglobin prior to inevitable hemolysis. Even if the jaundice is mildly worsened, this needs to be weighed against the improved cardiovascular stability and a reduced incidence of iron deficiency anemia that is seen in term infants and the reduction in necrotizing enterocolitis, late-onset sepsis, and intraventricular hemorrhage seen in preterm infants. One could argue that the only reason to perform immediate cord clamping in this situation would be that if you did not, you would plan to treat the jaundice by immediate phlebotomy of up to $200 \mathrm{ml}$ of blood, followed by immediate replacement. The only way this would be considered normally is by way of exchange transfusion if jaundice levels required this. Removing $200 \mathrm{~mL}$ of blood suddenly would cause too much cardiovascular instability. It is astonishing that we are happy to potentially deprive a newborn of this volume of blood at birth by prematurely clamping the cord. In all cases, it is important that the time at which cord clamping is done and the time of the first breath is clearly documented in the medical notes.

\section{Conclusion}

Immediate cord clamping is clearly not the biological norm. It has no proven benefits to the neonate and many proven harms. The use of immediate cord clamping has become so ingrained in recent obstetric practice that many "normal values" we take for granted (eg, normal neonatal heart rate, oxygen saturation, hemoglobin) are incorrectly based on neonates who have been subjected to this ill-conceived practice. If, for example, the normal range for neonatal hemoglobin was based on infants that had had delayed cord clamping, the concerns regarding polycythemia may not be present.

Delayed cord clamping has been proven to benefit term infants, with higher early hemoglobin concentration and increased iron reserves up to 6 months after birth, and no statistically significant increase in jaundice or polycythemia in the latest randomized controlled trial. ${ }^{1}$

Immediate cord clamping clearly has the potential to have far-reaching detrimental effects on the delicate developing neonatal brain. The long-term consequences of potential hypoxic brain injuries and the devastating sequelae of iron deficiency anemia on the developing brain should not be ignored. In 
preterm infants, the benefits are even more marked. Delaying cord clamping by $30-120$ seconds in preterm infants resulted in fewer babies requiring transfusions for anemia, better circulatory stability, a reduced risk of intraventricular hemorrhage (all grades), a decreased risk of necrotizing enterocolitis, and less late-onset sepsis. As more knowledge is gained in the field of cord blood stem cell research, it is possible that the benefits of waiting at least a minute may become even more compelling.

\section{Disclosure}

The authors report no conflicts of interest in this work.

\section{References}

1. Andersson O, Hellstrom-Westas L, Andersson D, Domellöf M. Effect of delayed versus early umbilical cord clamping on neonatal outcomes and iron status at 4 months: a randomised controlled trial. BMJ. 2011;343:d7157.

2. McDonald SJ, Middleton P, Dowswell T, Morris PS. Effect of timing of umbilical cord clamping of term infants on maternal and neonatal outcomes. Cochrane Database Syst Rev. 2013;7:CD004074.

3. Rabe H, Diaz-Rossello JL, Duley L, Dowswell T. Effect of timing of umbilical cord clamping and other strategies to influence placental transfusion at preterm birth on maternal and infant outcomes. Cochrane Database Syst Rev. 2012;8:CD003248.

4. Begley CM, Gyte GML, Devane D, McGuire W, Weeks A. Active versus expectant management for women in the third stage of labour. Cochrane Database Syst Rev. 2011;11:CD007412.

5. Magennis E. Analytical records - new inventions. Lancet. 1899;1373.

6. Dunn PM. Perinatal lessons from the past. Charles White (1728-1823) and natural birth. Arch Dis Child. 1990;65:395-396.

7. Darwin E. Zoonomia. Volume III. 3rd ed. London, UK; Johnson; 1801.

8. Brady JP, James LS, Baker MA. Heart rate changes in the fetus and newborn infant during labor, delivery and the immediate neonatal period. Am J Obstet Gynecol. 1962;84:1-12.

9. Bhatt S, Alison BJ, Wallace EM, et al. Delaying cord clamping until ventilation onset improves cardiovascular function at birth in preterm lambs. J Physiol. 2013;591 Pt 8:2113-2126.

10. Dawes GS, Mott JC, Widdicombe JG, Wyatt DG. Changes in the lungs of the new-born lamb. J Physiol. 1953;121:14-62.

11. Farrar D, Airey R, Law G, Tuffnell D, Cattle B, Duley L. Measuring placental transfusion for term births: weighing babies with cord intact. Br J ObstetGynaecol. 2011;118:70-75.

12. Mercer J, Erickson-Owens D, Skovgaard R. Cardiac asystole at birth: is hypovolaemic shock the cause? Med Hypotheses. 2009;72:458-463.

13. Vain NE, Satragno DS, Gorenstein AN, et al. Effect of gravity on volume of placental transfusion: a multicentre, randomised, non-inferiority trial. Lancet. 2014;384:235-240.

14. Niermeyer S, Velaphi S. Promoting physiologic transition at birth: re-examining resuscitation and the timing or cord clamping. Semin Fetal Neonatal Med. 2013;18:385-392.

15. Erickson-Owens DA, Mercer JS, Oh W. Umbilical cord milking in term infants delivered by caesarean section: a randomized controlled trial. J Perinatol. 2012;32:580-584.

16. Rabe H, Jewison A, Alvarez RF, et al; Brighton Perinatal Study Group. Milking compared with delayed cord clamping to increase placental transfusion in preterm neonates. Obstet Gynecol. 2011;117(2 Pt 1): 205-211.

17. Erickson-Owens DA and Mercer J. Feedback Letter re 1st McDonald Cochrane review. 21 April 2008 Pg 82 of: McDonald SJ, Middleton P, Dowswell T, Morris PS. Effect of timing of umbilical cord clamping of term infants on maternal and neonatal outcomes. Cochrane Database Syst Rev. 2013;7:CD004074.
18. Hutton EK, Hassan ES. Late vs early clamping of the umbilical cord in full-term neonates. Systematic review and meta-analysis of controlled trials. JAMA. 2007;297:1241-1252.

19. Backes $\mathrm{CH}$, Rivera BK, Haque U, et al. Placental transfusion strategies in very preterm neonates: a systematic review and meta-analysis. Obstet Gynecol. 2014;124:47-56.

20. Todorich B, Pasquini JM, Garcia CI, Paez PM, Connor JR. Oligodendrocytes and myelination: the role of iron. Glia. 2009;57:467-478.

21. Lozoll B, Beard J, Connor J, Barbara F, Georfieff M, Schallert T. Longlasting neural and behavioural effects of iron deficiency in infancy. Nutr Rev. 2006;64(5 Pt 2):S34-S43.

22. Cells 4 Life. Available from: http://www.cells4life.co.uk/. Accessed May 1, 2014.

23. Virgin Health Bank. Available from: http:/www.virginhealthbank.com/ why-bank-stem-cells/how-stem-cells-could-help-your-family. Accessed May 1, 2014.

24. Meier C, Middelanis J, Wasielewski B, et al. Spastic paresis after perinatal brain damage in rats is reduced by human cord blood mononuclear cells. Pediatr Res. 2006;59:244-249.

25. ClinicalTrials.gov. Safety and effectiveness of cord blood stem cell infusion for the treatment of cerebral palsy in children. Trial identifier NCT01072370. Available from: http://clinicaltrials.gov/show/ NCT01072370. Accessed August 6, 2014.

26. ClinicalTrials.gov. Cord blood for neonatal hypoxic-ischemic encephalopathy. Trial identifier NCT00593242. Available from: http:// clinicaltrials.gov/show/NCT00593242. Accessed August 6, 2014.

27. ClinicalTrials.gov. Autologous cord blood stem cells for autism. Trial identifier NCT01638819. Available from: http://clinicaltrials.gov/show/ NCT01638819. Accessed August 6, 2014.

28. ClinicalTrials.gov. Umbilical cord blood in the treatment of stroke in children. Trial identifier: NCT01700166. Available from: http://clinicaltrials.gov/show/NCT01700166. Accessed August 6, 2014.

29. ClinicalTrials.gov. Safety study of umbilical cord blood to treat pediatric traumatic brain injury. Trial identifier NCT01251003. Available from: http://clinicaltrials.gov/show/NCT01251003. Accessed August 6, 2014.

30. ClinicalTrials.gov. Cord blood infusion plus vitamin D and omega 3 fatty acid supplementation to preserve beta cells in children with recent onset type 1 diabetes. Trial identifier NCT00873925. Available from: http:// clinicaltrials.gov/show/NCT00873925. Accessed August 6, 2014.

31. ClinicalTrials.gov. A randomized study of autologous umbilical cord blood reinfusion in children with cerebral palsy. Trial identifier NCT01147653. Available from: http://clinicaltrials.gov/show/ NCT01147653. Accessed August 6, 2014.

32. Duke Translational Medicine Institute. Kurtzberg and team move forward with cerebral palsy cord blood study. Available from: https:// www.dtmi.duke.edu/news-publications/news/dtmi-news-archives/ kurtzberg-and-team-move-forward-with-cerebral-palsy-cord-bloodstudy. Accessed May 1, 2014.

33. Drummond PM, Colver AF. Analysis by gestational age of cerebral palsy in singleton births in north-east England 1970-1994. PaediatrPerinatEpidemiol. 2002;16:172-180.

34. Prendville WJ, Harding JE, Elbourne DR, Stirrat GM. The Bristol third stage trial: active versus physiological management of third stage of labour. BMJ. 1988;297:1295-1300.

35. Magnusson C, Rai D, Goodman A, et al. Migration and autism spectrum disorder: population-based study. Br J Psychiatry. 2012;201:109-115.

36. Gardener H1, Spiegelman D, Buka SL. Perinatal and neonatal risk factors for autism: a comprehensive meta-analysis. Pediatrics. 2011;128:344-355.

37. Hansen TWR. Kernicterus in term and near-term infants - the spectre walks again. ActaPaediatr. 2000;89:1155-1157.

38. Zimmermanm HM, Yannet H. Kernicterus: jaundice of the nuclear masses of the brain. Am J Dis Child. 1933;45:740-759.

39. Lucey JG, Hibbard E, Behrman RE, et al. Kernicterus in asphyxiated newborn monkeys. Exp Neurol. 1964;9:43-58.

40. Hutchon D. Evolution of neonatal resuscitation with intact placental circulation. Infant. 2014;10:58-61. 
41. American College of Obstetricians and Gynecologists. ACOG Committee Opinion No 399. Umbilical cord blood banking. ACOG Committee Opinion No 399. Obstet Gynecol. 2008;111: 475-477.

42. Wilberg N, Kallen K, Olofsson P. Delayed umbilical cord clamping at birth has effects on arterial and venous blood gases and lactate concentrations. BJOG. 2008;115:697-703.

43. World Health Organization. Delayed clamping of the umbilical cord to reduce infant anaemia. 2013. Available from: http://www.mchip.net/ sites/default/files/DCC\%20Briefer.pdf. Accessed May 1, 2014.

44. Royal College of Obstetricians and Gynaecologists. 2013 Statement on Cochrane review on the timing of cord clamping. Available from: http://www.rcog.org.uk/news/rcog-statement-cochrane-review-timingcord-clamping. Accessed May 9, 2014.

45. Royal College of Obstetricians and Gynaecologists. Green-top Guideline No 52. Prevention and management of postpartum haemorrhage. 2009. Available from:http://www.rcog.org.uk/womens-health/clinicalguidance/prevention-and-management-postpartum-haemorrhagegreen-top-52. Accessed May 9, 2014.
46. Resuscitation Council (UK). Resuscitation Guidelines 2010 - Newborn life support. Available from: http://www.resus.org.uk/pages/nls.pdf. Accessed May 9, 2014.

47. International Confederation of Midwives. Prevention and treatment of post-partum haemorrhage: new advances for low resource settings. 2006. Available from: http://www.pphprevention.org/files/FIGO-ICM_ Statement_November2006_Final.pdf. Accessed August 6, 2014.

48. Perlman JM, Wyllie J, Kattwinkel J, et al; on behalf of the Neonatal Resuscitation Chapter Collaborators. Part 11: neonatal resuscitation: 2010 International Consensus on Cardiopulmonary Resuscitation and Emergency. Cardiovascular Care Science With Treatment Recommendations. Circulation. 2010;122 Suppl 2:S516-S538.

49. European Resuscitation Council. Guidelines for resuscitation. 2010 Available from: https://www.erc.edu/index.php/doclibrary/en/209/1/ Accessed May 9, 2014.

\section{Publish your work in this journal}

Pediatric Health, Medicine and Therapeutics is an international, peerreviewed, open access journal publishing original research, reports, editorials, reviews and commentaries. All aspects of health maintenance, preventative measures and disease treatment interventions are addressed within the journal. Practitioners from all disciplines are invited to submit

\section{Dovepress}

their work as well as healthcare researchers and patient support groups. The manuscript management system is completely online and includes a very quick and fair peer-review system. Visit http://www.dovepress.com/ testimonials.php to read real quotes from published authors.

Submit your manuscript here: http://www.dovepress.com/pediatric-health-medicine-and-therapeutics-journal 